\title{
Short-Term Effect of Transition from Conventional to Automated Milking on Teat Skin and Teat End Condition
}

\author{
S. De Vliegher, ${ }^{*}$ H. Laevens, ${ }^{1}$ H. W. Barkema, $\dagger$ G. Opsomer, ${ }^{*}$ T. Hemling,‡ and A. de Kruif ${ }^{\star}$ \\ *Department of Reproduction, Obstetrics and Herd Health, \\ Faculty of Veterinary Medicine, Ghent University, Merelbeke, Belgium \\ †Department of Health Management, Atlantic Veterinary College, \\ University of Prince Edward Island, Charlottetown, Canada \\ ‡DeLaval International, Business Unit Hygiene, Kansas City, MO
}

\begin{abstract}
A higher milking frequency, as a consequence of milking with an automated milking system, incorporates a threat to teat condition. To study the effect of transition from conventional to automated milking on teat skin and teat end condition, 40 lactating Holstein-Friesian cows and heifers from a high yielding dairy herd were randomly allocated to either a conventional or an automated milking system group. In the latter group, automated milking was initiated during the study period, while conventional milking was continued in the control group. Teat skin and teat end condition were evaluated weekly on quarter level for all animals from $5 \mathrm{wk}$ before until 8 wk after transition. A high emollient iodine teat dip was used on all cows during the study period.

Teat skin condition of the animals in the automated milking system group was consistent from before and during milking with the automated milking system. Rear teats had a better skin and end condition than front teats. Evolution of teat end condition over time between the automated and conventional milking groups was not statistically different. Heifers, however, seemed to be more sensitive to the change than multiparous cows, as their teat end condition slightly decreased. (Key words: automated milking, teat end condition, teat skin condition)
\end{abstract}

Abbreviation key: AMS = automated milking system, $\mathbf{C M S}=$ conventional milking system, $\mathbf{P A R}=$ parity, $\mathbf{T P}=$ teat position, $\mathbf{T E S}=$ teat end score, $\mathbf{T S S}=$ teat skin score.

\section{INTRODUCTION}

Teat end callosity increases the incidence of clinical mastitis (Neijenhuis et al., 2001b), and teat end condi-

\footnotetext{
Received August 8, 2002.

Accepted December 6, 2002.

Corresponding author: S. De Vliegher; e-mail: Sarne.Devliegher@ rug.ac.be.

${ }^{1}$ Current address: Coordination Centre for Veterinary Diagnostics, Veterinary and Agrochemical Research Centre, Brussels, Belgium.
}

tion is associated with the occurrence of intramammary Staphylococcus aureus infections (Goldberg et al., 1994; Zadoks et al., 2001). It is, therefore, of paramount importance to preserve the best teat skin and teat end condition in the dairy herd, whether the cows are milked conventionally or automatically.

The introduction of an automated milking system (AMS) in a dairy herd represents a major change in the way cows are milked. One of the most obvious changes is that using an AMS, cows are milked more frequently than when using a conventional milking system (CMS). At each milking, the cow's teats are spray cleaned with warm water, dried, milked, and disinfected, actions with a potential negative effect on teat condition. Moreover, shorter milking intervals leave less time for teat tissue to recover (Rasmussen et al., 2001). Neijenhuis et al. (2001a) suggested problems may arise with increasing milking frequency, given that the recovery of teat condition took more time than expected.

A second alteration when changing to automated milking is that this milking technique is based on milking of the individual quarter instead of the individual cow. This should prove an advantage when considering mastitis detection and avoiding of over-milking of front quarters and should therefore benefit teat condition and udder health (Rasmussen et al., 2001).

As no data are available on the changes of teat condition during and following transition from conventional to automated milking, the purpose of this study was to quantify the effects of the introduction of a specific AMS on teat condition.

\section{MATERIALS AND METHODS}

\section{Herd and Animals}

Data were collected on the research dairy farm of Ghent University (Biocentrum Agri-Vet, Melle, Belgium), where a new free-stall barn with cubicles and AMS (Voluntary Milking System, VMS, DeLaval, Tumba, Sweden) were installed. The herd consisted of 
Table 1. Housing and milking of the animals in the conventional (CMS) and automated milking system (AMS) group, from 5 wk before until 8 wk after initiation of the AMS.

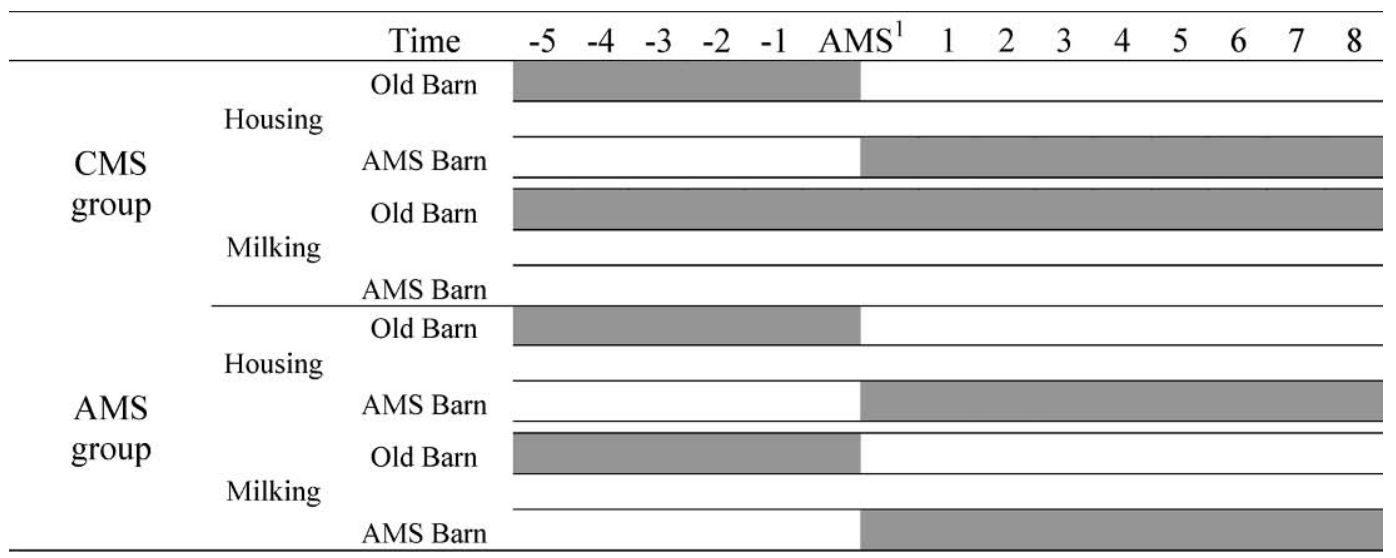

${ }^{1}$ Initiation of automated milking of the animals in the AMS group.

approximately 60 Black Holstein-Friesian cows. Mean $305-\mathrm{d}$ production was $9312 \mathrm{~kg}$.

\section{Study Design}

A randomized clinical trial was conducted during a 14-wk period from February 2001 to May 2001. From all lactating heifers and cows in the herd, 40 animals were selected according to the expectation that they would not give behavioral problems when the AMS was in use. These 40 animals were allocated to either the CMS (control) group $(\mathrm{n}=20)$ or the AMS group ( $\mathrm{n}=$ 20). Stratification was done for parity: each group consisted of 9 heifers and 11 multiparous cows.

During the first 5 wk of the trial, both groups were housed in the same free-stall barn and were milked with a CMS (Fullwood Packo Group, Zedelgem, Belgium). This was a double-five herringbone milking parlor, with a $43-\mathrm{kPa}$ nominal vacuum, milk recorder jars, and automatic cluster removal. Premilking udder hygiene was performed by dry wiping of the teats with individual paper towels. Postmilking teat dipping was applied (Proactive Plus, $0.15 \%$ iodine, $4 \%$ glycerine and $4 \%$ sorbitol based emollient, DeLaval, Drongen, Belgium). Three months before the beginning of the study, all teat liners of the CMS were renewed.

Five weeks after teat scoring started, both AMS and CMS groups were moved to the new free-stall barn, and at that moment, the AMS started milking the 20 animals of the AMS group. In this particular system cleaning of teats and premilking treatment consisted of a combination of water, air pressure, and air vacuum. Postmilking teat disinfection was applied, using a spraying device mounted on the robotic arm.

On all 40 animals the same teat disinfection product (Proactive Plus) was used during the whole study pe- riod. Two times daily, the heifers and cows in the CMS group were moved to the old barn to be milked with the CMS (Table 1).

\section{Data Collection}

Teat skin score (TSS) and teat end score (TES) were evaluated weekly on quarter level for all 40 cows based on the scoring system developed at the University of Vermont (Goldberg et al., 1994) (Table 2). Teat condition was scored five times before and eight times after AMS initiation, giving 2080 expected scores per response variable. During the week of the AMS start-up, no scores were recorded. The same person evaluated teat skin and teat end condition throughout the study and was trained before the study period. Scoring was blinded as long as all cows were milked in the conventional way. When automated milking started, scoring was not blinded for obvious reasons. Scoring of teat skin and teat end condition was performed by means of palpation and visual inspection and was completed immediately after milking and before postmilking teat disinfection. The AMS recorded milking frequency per day per animal. For one heifer and one multiparous cow these data were not available in the system.

\section{Statistical Analysis}

Before statistical analysis, all data were checked for outliers. No data were excluded for this reason. Randomization of the animals was checked by comparing mean production data and DIM prior to the start of the study between groups using independent sample T-tests. Pearson correlation coefficient ( $r$ ) between TSS and TES was calculated (SPSS 10.0 for Windows, SPSS Inc., Chicago, IL). 
Table 2. Teat skin score (TSS) and teat end score (TES) evaluation table (based on the University of Vermont scoring system, Goldberg et al., 1994).

\begin{tabular}{ll}
\hline TSS & Description \\
\hline 1 & Smooth supple skin free from scales, cracks or chapping \\
1.5 & Very slight drying of the skin \\
2 & Slight drying of skin with superficial skin flaking \\
2.5 & Dry skin with flaking. No cracks present \\
3 & More severe drying, with early cracks present. Skin cracks do not have severe red fissures \\
& at the base \\
3.5 & Teat skin is chapped with cracks. \\
4 & More teat skin is chapped with pronounced cracks present. Redness, indicating inflammation \\
4.5 & is present. Some scabbed, healing lesions may be present \\
5 & Skin damages with deep chaps \\
TES & Severe skin damage with deep cracks and open ulcerative lesions or scabs \\
1 & Smooth teat end and sphincter with no evidence of roughness. \\
1.5 & Very slight irregularities near the orifice \\
2 & Slight irregularities or fringes of roughness near orifice. \\
2.5 & Teat end sphincter is barely roughened with radial cracks \\
3 & Teat end sphincter is moderately roughened with radial cracks. \\
3.5 & Teat orifice is significantly roughened with radial cracks \\
4 & Teat orifice is significantly roughened with pronounced radial cracking. \\
4.5 & Teat end is severely roughened with pronounced radial cracking \\
5 & Teat end is severely roughened and with deep irregular callous. \\
\hline
\end{tabular}

Statistical analysis was performed using the MIXED procedure (SAS Version 8.02, SAS Institute Inc., Cary, $\mathrm{NC)}$ with teat within cow as the unit of analysis. A backward stepwise modeling procedure was used to eliminate terms from the initial models. A first-order autoregressive covariance structure was used to model the autocorrelation in the residual error in the repeated measures of the response variables. Degrees of freedom were calculated using the Satterthwaithe method. Statistical significance was defined at $P \leq 0.05$.

Models were fitted for TSS and TES as outcome variables for all heifers and multiparous cows in the study. The initial models used were as follows:

$$
\begin{aligned}
& \mathrm{TSS}_{\mathrm{ijklmn}} \text { or } \mathrm{TES}_{\mathrm{ijklmn}}= \\
& \mu+\text { GROUP }_{i}+\text { PAR }_{\mathrm{j}}+\left(\text { GROUP } \times \text { PAR }_{i j}\right. \\
& +\mathrm{COW}(\text { GROUP PAR })_{\mathrm{k}(\mathrm{ij})}+\mathrm{TP}_{1}+(\mathrm{GROUP} \times \mathrm{TP})_{\mathrm{il}} \\
& +(\mathrm{PAR} \times \mathrm{TP})_{\mathrm{jl}}+\mathrm{TEAT}(\mathrm{COW})_{\mathrm{m}(\mathrm{k})}+\mathrm{WEEK}_{\mathrm{n}} \\
& +(\text { GROUP } \times \text { WEEK })_{\text {in }}+(\text { PAR } \times \text { WEEK })_{\text {jn }} \\
& +(\mathrm{TP} \times \mathrm{WEEK})_{\mathrm{ln}}+(\text { GROUP } \times \mathrm{PAR} \times \mathrm{WEEK})_{\mathrm{ijn}} \\
& +(\text { GROUP } \times \mathrm{TP} \times \mathrm{WEEK})_{\mathrm{iln}}+\varepsilon_{\mathrm{ijklmn}}
\end{aligned}
$$

where $\mathrm{TSS}_{\mathrm{ijklmn}}=$ Teat skin score, $\mathrm{TES}_{\mathrm{ijk} l m n}=$ Teat end score, $\mu=$ overall mean, GROUP ${ }_{i}=$ fixed effect of group $[\mathrm{CMS}(\mathrm{i}=0)$ versus AMS group $(\mathrm{i}=1)], \mathrm{PAR}_{\mathrm{j}}=$ fixed effect of parity [heifer $(j=0)$ versus multiparous cow $(j$ $=1)], \mathrm{COW}(\text { GROUP PAR })_{\mathrm{k}(\mathrm{ij})}=$ random effect of COW $\mathrm{k}(1$ to 40$)$ nested within GROUP $\mathrm{i}$ and PAR j, $\mathrm{TP}_{1}=$ fixed effect of teat placement [front $(l=0)$ versus rear teat $(\mathrm{l}=1)$ ], TEAT $(\mathrm{COW})_{\mathrm{m}(\mathrm{k})}=$ TEAT $\mathrm{m}$ within $\mathrm{COW} \mathrm{k}$ as unit of analysis ( $m=1$ to 160$), \mathrm{WEEK}_{\mathrm{n}}=$ repeated measurement ( $\mathrm{n}=0$ to 8 , week 0 being the average score of the five teat skin or teat end scores recorded prior to robotic milking initiation), and $\varepsilon_{\mathrm{ijk} k \mathrm{mn}}=$ random error term.

\section{RESULTS}

At the start of the study, the animals were on average $138( \pm 14)$ DIM. For the CMS animals this was $152( \pm$ $25)$ and for the AMS animals $123( \pm 12)$ DIM $(P=0.31)$. The CMS and AMS group produced $33.1( \pm 1.8)$ and $33.1( \pm 1.6) \mathrm{kg}$ of milk per day, respectively $(P=0.99)$. Overall, 2045 TSS (1.7\% missing values) and 2034 TES (2.2\% missing values) were recorded during the 14 -wk trial period. Teat skin score and TES were correlated slightly $(\mathrm{r}=0.098, P<0.0001)$.

Average milking frequency per day, after initiation of the AMS, was $2.55( \pm 0.01)$ and $2.63( \pm 0.01)$ for heifers and multiparous cows in the AMS group, respectively. Heifers in the AMS group were hence milked every 9 $\mathrm{h}$ and $24 \mathrm{~min}$ and multiparous cows every $9 \mathrm{~h}$ and 6 min on average during the respective period. Minimum and maximum milking frequencies were 1.7 and 3.2 for heifers, and 1.7 and 3.5 for multiparous cows. Both heifers and cows showed a steady increase in mean milking frequency during the first weeks after the start of automated milking, stabilizing at wk 5 (Figure 1). One week later, a second increase was seen in the multiparous cows.

\section{Teat Skin Condition}

Teat skin condition of all animals in the study was good during the 5 wk before AMS start-up, with both 


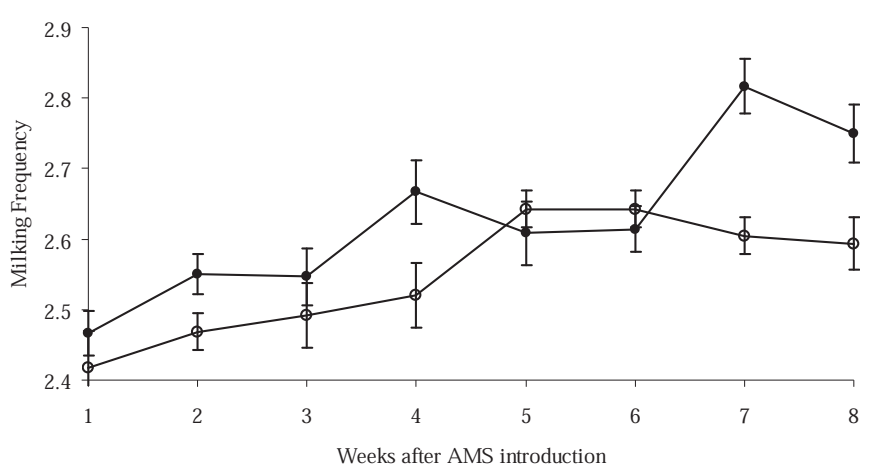

Figure 1. Mean ( \pm SEM) milking frequency per cow per day for heifers $(O)$ and multiparous cows $(\bullet)$ in the automated milking system (AMS) group, from 1 wk to 8 wk after initiation of the AMS.

groups and parities having similar scores (Figure 2). In Table 3, the final model of TSS is presented. Least squares means for the CMS and AMS group were 1.33 $( \pm 0.05)$ and $1.22( \pm 0.05)(P=0.14)$. Over time, TSS evolved differently for the animals in the two groups (Figure $2 ; P<0.0001$ ). After introduction of the AMS, TSS increased slightly in both CMS heifers and CMS cows to return to the level from before introduction of the AMS at wk 6. In the AMS group, on the other hand, scores remained stable for both heifers and multiparous cow (Figure 2). Rear teats (LSM $=1.20 \pm 0.04$ ) had a better skin condition than front teats (LSM $=1.35 \pm$ 0.04) $(P<0.0001)$. Before AMS start-up, a difference between rear and front teats of animals in both groups already existed, with rear teats having a better skin condition (Figure 3 ). This difference stayed more or less the same during the weeks after AMS initiation in both CMS and AMS animals.

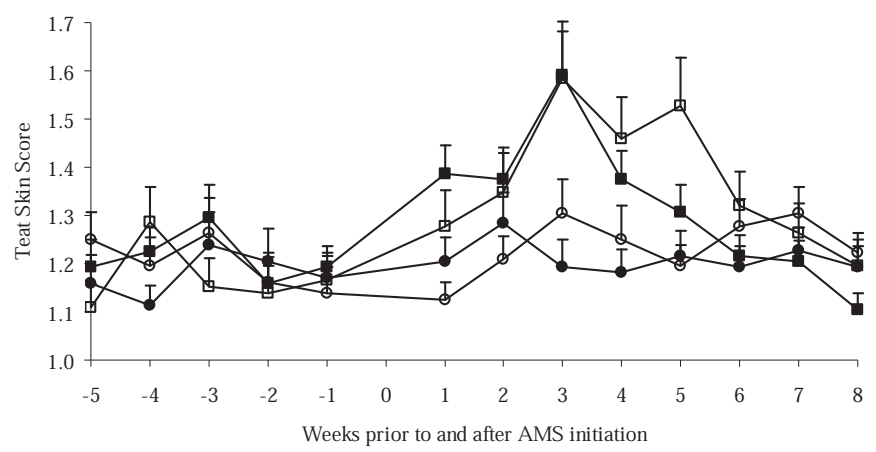

Figure 2. Mean (+SEM) teat skin score for heifers $(\square)$ and multiparous cows $(\mathbf{\square})$ in the conventional milking system group and for heifers $(\bigcirc)$ and multiparous cows $(-)$ in the automated milking system (AMS) group, from 5 wk before to 8 wk after initiation of the AMS (wk 0).
Table 3. Variables in the final model of teat skin score (TSS).

\begin{tabular}{lccc}
\hline Variable & df & F & $P$ \\
\hline GROUP $^{1}$ & 38 & 2.27 & 0.14 \\
TP & 291 & 41.75 & $<0.0001$ \\
WEEK & 899 & 8.76 & $<0.0001$ \\
GROUP $\times$ WEEK & 899 & 7.54 & $<0.0001$ \\
\hline${ }^{1}$ GROUP: conventional milking system versus automated milking. \\
'2 TP: teat position, front versus rear teat.
\end{tabular}

\section{Teat End Condition}

Teat end condition of all animals in the study was good during the first 5 wk of the study and in both AMS and CMS groups. Heifers had slightly better teat end conditions than multiparous cows (Figure 4). In Table 4 the final model of TES is presented. Teat end condition was not different between groups $(P=0.97)$. After the AMS introduction, TES for heifers and multiparous cows evolved slightly different $(P=0.04)$. Teat end score from the CMS heifers evolved differently over time in comparison with the CMS multiparous cows $(P=0.02)$, but not differently from the AMS heifers $(P=0.28)$. Teat end score from the AMS multiparous cows evolved differently over time compared with the AMS heifers $(P=0.03)$, and differently from the CMS multiparous cows $(P=0.001)$. Rear teats $(\mathrm{LSM}=1.32 \pm 0.06)$ had a somewhat better teat end condition than front teats $(\mathrm{LSM}=1.39 \pm 0.06)(P=0.03)$. The difference between rear and front teats in TES of the AMS milked animals decreased over time (Figure 5).

\section{DISCUSSION}

Overall, data collected during milking with the CMS prior to AMS start-up show a good teat skin and teat end condition of the animals in this study. Postmilking

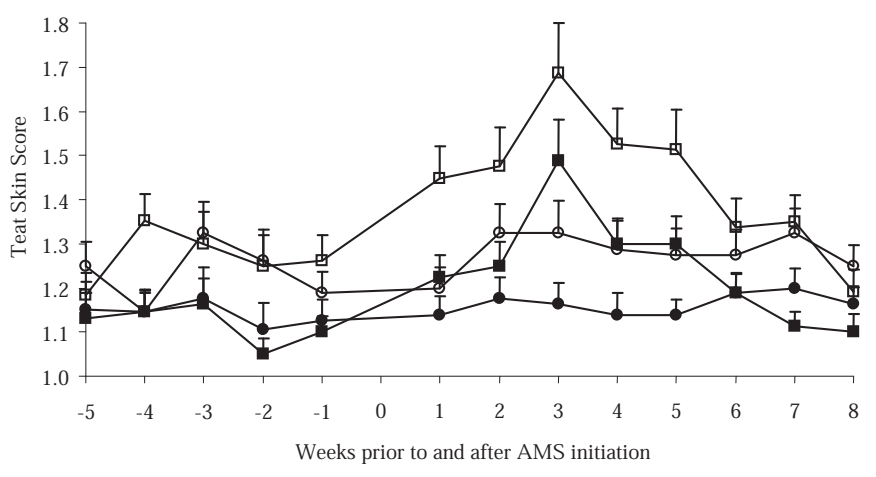

Figure 3. Mean (+ SEM) teat skin score for front $(\square)$ and rear teats $(\square)$ in the conventional milking system group and for front $(\bigcirc)$ and rear teats (-) in the automated milking system (AMS) group, from 5 wk before to 8 wk after initiation of the AMS (wk 0). 


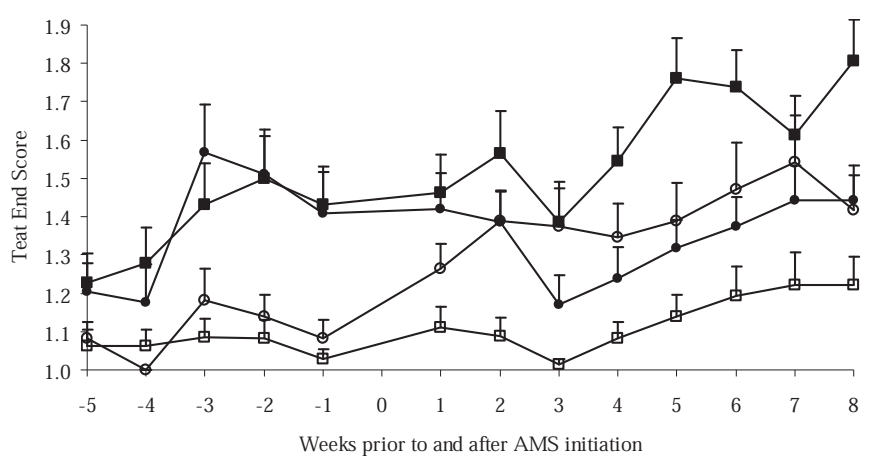

Figure 4. Mean (+ SEM) teat end score for heifers $(\square)$ and multiparous cows ( $\mathbf{\square})$ in the conventional milking system group and for heifers $(\bigcirc)$ and multiparous cows $($ ) in the automated milking system (AMS) group, from 5 wk before until 8 wk after initiation of the AMS (wk 0).

teat disinfection was applied on all animals, no major udder health problems were reported, and the milking machine in the herd was well maintained.

Teat skin condition of the AMS animals was not influenced much by the new milking procedure, as TSS remained stable and consistent during the 8 -wk period following AMS introduction. The higher milking frequency as a result of automated milking did not affect the teat skin condition although at each milking, teats were spray cleaned with warm water, dried, and milked, and postmilking teat sprayed. The use of a high emollient teat dip with a mild surfactant system may have mitigated for the greater part the negative effect of more frequent milking on teat skin condition (Mein et al., 2001), although this has to be confirmed by further studies. The healing benefit of $10 \%$ glycerine in a teat dip composition has, however, been shown before (Fox et al., 1991; Fox, 1992). The CMS group, on the other hand, showed a decrease in teat skin condition (increase in TSS) over time. This was rather strange as the only variable that changed was housing. An influence of this factor, however, should also have been noticed in the AMS group as they also moved to the same new free-

Table 4. Variables in the final model of teat end score (TES).

\begin{tabular}{lrlc}
\hline Variable & df & F & $P$ \\
\hline GROUP $^{1}$ & 36 & 0.00 & 0.97 \\
PAR $^{2}$ & 36 & 3.00 & 0.09 \\
TP $^{3}$ & 233 & 4.73 & 0.03 \\
WEEK & 928 & 7.72 & $<0.0001$ \\
GROUP $\times$ PAR & 36 & 3.48 & 0.07 \\
GROUP $\times$ WEEK & 928 & 1.73 & 0.09 \\
PAR $\times$ WEEK & 928 & 2.05 & 0.04 \\
GROUP $\times$ PAR $\times$ WEEK & 928 & 2.51 & 0.01 \\
\hline
\end{tabular}

${ }^{1}$ GROUP: conventional milking system versus automated milking.

${ }^{2}$ PAR: parity: heifers versus multiparous cows.

${ }^{3} \mathrm{TP}$ : teat position, front versus rear teat.

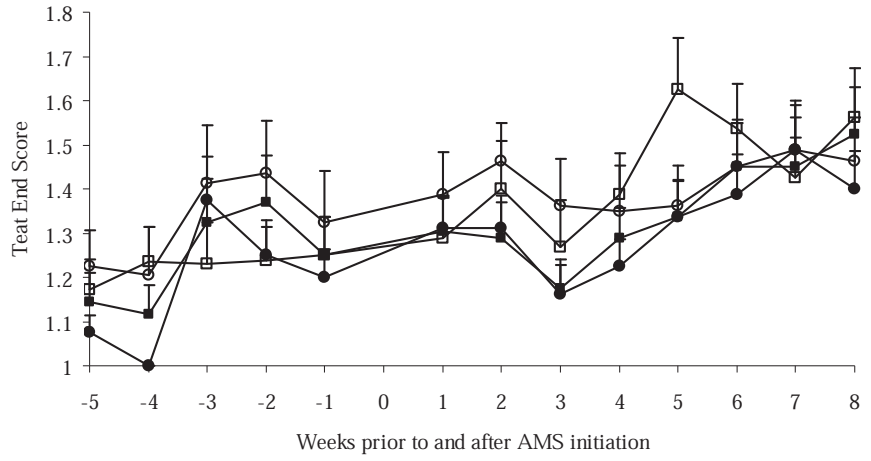

Figure 5. Mean (+ SEM) teat end score for front $(\square)$ and rear teats $(\square)$ in the conventional milking system group and for front $(O)$ and rear teats (-) in the automated milking system (AMS) group, from 5 wk before to 8 wk after initiation of the AMS (wk 0).

stall barn. Moreover, the animals in this CMS group were milked in the same way as before, which means that the milking procedure cannot explain this increase. The fact that the animals in the latter group, once automated milking was started, needed to be moved twice daily from the new to the old barn to be milked by the CMS may elucidate this finding. They had to wait approximately 15 min two times per day outside in between the new and old free-stall barns and were at that moment exposed to wind and temperature changes. This was not the fact for the AMS animals, which were kept inside during the whole study. Harsh weather in combination with a fluid (teat dip after milking) hastens chapping of teats during cold and windy conditions (Fox and Norell, 1994). Although average wind speed, temperature, and relative humidity during the study were $13.5 \mathrm{~km} / \mathrm{h}$ (range: 4.0 to $24 \mathrm{~km} / \mathrm{h}$ ), $7.5^{\circ} \mathrm{C}$ (range: 0.1 to $14.6^{\circ} \mathrm{C}$ ), and $86.5 \%$ (range: 70.1 to $97.3 \%$ ), respectively, showing mild averages, we believe it negatively influenced the teat skin condition of the CMS group. The fact that rear teats had a better TSS than front teats could partly be explained by the better protection of rear teats against environmental influences by the hind legs.

Teat end condition was expected to be influenced more by the milking procedure than was teat skin condition. This was reflected by the difference in TES between heifers and multiparous cows before switching to automated milking and in the CMS group after automated milking was started: heifers have not been milked as often as multiparous cows and hence have been less under threat of the milking machine. This was in agreement with Neijenhuis et al. (2000), who found less-callused teats in first-lactation cows compared with older cows (parity $>2$ ). In the AMS group, however, the milking procedure changed, leading to a slight increase of TES in heifers, while in the multipa- 
rous cows a slight decrease was noticed. Heifers seemed, therefore, more sensitive to switching from conventional to automated milking than multiparous cows, and should therefore be monitored closely during the transition period. The finding that rear teats had a little better end condition when compared to front teats could be explained by the fact that front teats are more likely to be over-milked in the CMS as front quarters produce less milk than rear quarters. Even with an automatic cluster remover, the cows are still milked on cow-level and therefore the differences between quarters are not accounted for. This finding was in agreement with another study where front teats were more callused and had a higher level of thickness than rear teats (Neijenhuis et al., 2000). This difference was expected to be neutralized in the AMS-milked animals, as then quarter-level milking was commenced. In the final model, nevertheless, the difference was still present in both CMS and AMS groups. However, in Figure 5 , it can be seen that the difference in teat end condition between front and rear teats diminishes over time. It has, on the other hand, to be noted that this was due to a slight increase of TES of the rear teats, instead of the expected decrease of TES of the front teats, as front quarters were subject to over-milking more than rear quarters. The increased milking frequency did not influence teat end condition of the AMS animals significantly, although heifers in this group were more sensitive. It was rather surprising that TES of the AMS group was influenced so little as the more a quarter is milked the more it is subject to the effects of the milking machine. Moreover, the shorter milking interval will leave shorter time for teat tissue to recover (Rasmussen et al., 2001), and it was recently discovered that teat recovery after milking took more time than expected with milking intervals shorter than $8 \mathrm{~h}$ leading to incomplete recovery (Neijenhuis et al., 2001a).

Teat skin and teat end condition were correlated only slightly in this study, indicating that both variables are for the greater part influenced by different parameters. According to Mein et al. (2001), major factors affecting teat end condition are seasonal weather changes, teat end shape, production level, stage of lactation, and interactions between milking management and machine (especially slow milking and over-milking). A difference in production levels between groups was not present in this study, but neither production data nor stage of lactation were included in the analysis.

More studies, with extended duration and on more automated milking systems and herds are needed to confirm the results from the present study. A specific AMS (VMS, DeLaval) and high emollient teat dip (Proactive Plus, DeLaval) were used in this study. It is not known whether the conclusions about the effects on
TES and TSS can be applied to other systems. Variability in scores was small on this farm leading to small differences in scores being statistically significant. The biological significance of these difference is, however, not always clear. It could be that the current scorings tables in use are not able to capture biological important (but small) differences in TSS or TES. Additionally, it could also be that teat condition on this particular farm was extremely good, whereas on other farms changes and variability might be larger. Further research should elucidate this. Besides the aforementioned variables other variables, e.g., production data, teat shape, machine-on-time, lactation stage, udder health and genetic influences should be taken into consideration in additional studies. The interaction of teat dip composition variables and AMS machine variables should also be investigated further.

\section{CONCLUSIONS}

Changing from conventional to automated milking leads to an increased milking frequency. Monitoring the transition period on one farm switching to a particular automated milking system revealed that neither teat skin nor teat end condition were very influenced. Special attention should, however, be given to heifers as the present data suggest that they are more sensitive to this change than multiparous cows, considering teat end condition.

\section{ACKNOWLEDGMENTS}

The authors gratefully thank J. Christiaens, G. Eeckhaut, M. McKinzie, I. Laquiere, N. Ben Rhouma, K. Vermeulen, G. Foucqaert, and S. Willaert for their excellent support in conducting this study.

\section{REFERENCES}

Fox, L. K. 1992. Colonization by Staphylococcus aureus on chapped teat skin: Effect of iodine and chlorhexidine post-milking disinfectants. J. Dairy Sci. 75:66-71.

Fox, L. K., and R. J. Norell. 1994. Staphylococcus aureus colonization of teat skin as affected by postmilking teat treatment when exposed to cold and windy condition. J. Dairy Sci. 77:2281-2288.

Fox, L. K, J. A. Nagy, J. K. Hillers, J. D. Cronrath, and D. A. Ratkowsky. 1991. Effects of post-milking teat treatment on the colonization of Staphylococcus aureus on chapped teat skin. Am. J. Vet. Res. 52:799-802.

Goldberg, J. J., P. A. Murdough, A. B. Howard, P. A. Drechsler, J. W. Pankey, G. A. Ledbetter, L. L. Day, and J. D. Day. 1994. Winter evaluation of a postmilking powdered teat dip. J. Dairy Sci. 77:748-758.

Mein, G. A., F. Neijenhuis, W. F. Morgan, D. J. Reinemann, J. E. Hillerton, J. R. Baines, I. Ohnstad, M. D. Rasmussen, L. Timms, J. S. Britt, R. Farnsworth, N. Cook, and T. Hemling. 2001. Evaluation of bovine teat condition in commercial dairy herds: 1 . Noninfectious factors. Pages 347-351 in Proc. 2nd Int. Symp. on Mastitis and Milk Quality, Vancouver, BC, Canada. 
Neijenhuis, F., H. W. Barkema, H. Hogeveen, and J. P. T. M. Noordhuizen. 2000. Classification and longitudinal examination of callused teat ends in dairy cows. J. Dairy Sci. 83:2795-2804.

Neijenhuis, F., G. H. Klungel, and H. Hogeveen. 2001a. Recovery of cow teats after milking as determined by ultrasonographic scanning. J. Dairy Sci. 84:2599-2606.

Neijenhuis, F., H. W. Barkema, H. Hogeveen, and J.P.T.M. Noordhuizen. 2001b. Relationship between teat-end callosity and occurrence of clinical mastitis. J. Dairy Sci. 84:2664-2672.
Rasmussen, M. D., J. Y. de Blom, L. A. H. Nielsen, and P. Justesen. 2001. The impact of automatic milking on udder health. Pages 397-400 in Proc. 2nd Int. Symp. on Mastitis and Milk Quality, Vancouver, BC, Canada.

Zadoks, R. N., H. G. Allore, H. W. Barkema, O. C. Sampimon, G. J. Wellenberg, Y. T. Grhn, and Y. H. Schukken. 2001. Cow- and quarter-level risk factors for Streptococcus uberis and Staphylococcus aureus mastitis. J. Dairy Sci. 84:2649-2663. 